Proceeding Paper

\title{
Enabling Decision-Making Analytics for Collaborative Information Exchanges of Digital Precinct Models ${ }^{\dagger}$
}

\author{
Otto Newhouse *, Hoon Han (D) and Gloria Pignatta (iD) \\ School of Built Environment, University of New South Wales (UNSW), Sydney, NSW 2052, Australia; \\ h.han@unsw.edu.au (H.H.); g.pignatta@unsw.edu.au (G.P.) \\ * Correspondence: o.newhouse@unsw.edu.au \\ † Presented at the 3rd Built Environment Research Forum, Sydney, Australia, 1 December 2021
}

\begin{abstract}
This research identifies patterns of conflicting interorganisational information exchange requirements in precinct modelling and simulation $(M \& S)$ depending on the interaction and expertise of the collaborating actors. Internationally surveying leading experts, it extends multicriteria decision analysis with partitioning matrices of superposed orders from the eigenvectors of comparative datasets. The results are applied to real-world industry tasks and exchanges established for building M\&S to combine and reuse them as models for precinct assets including energy infrastructure and also for supporting modular information exchanges between digital precinct models.
\end{abstract}

Keywords: process modelling; matrix superposition; business process choreography; BPMN; MCDA; multicriteria decision analytics; analytic hierarchy process; AHP; open BIM

\section{Introduction}

Model-driven individually designed energy-smart buildings can save energy and

check for updates

Citation: Newhouse, O.; Han, H.; Pignatta, G. Enabling DecisionMaking Analytics for Collaborative Information Exchanges of Digital Precinct Models. Environ. Sci. Proc. 2021, 12, 14. https://doi.org/ 10.3390/environsciproc2021012014

Academic Editor: Khan Rahmat Ullah

Published: 25 February 2022

Publisher's Note: MDPI stays neutral with regard to jurisdictional claims in published maps and institutional affiliations.

Copyright: (C) 2022 by the authors. Licensee MDPI, Basel, Switzerland. This article is an open access article distributed under the terms and conditions of the Creative Commons Attribution (CC BY) license (https:// creativecommons.org/licenses/by/ $4.0 /)$. energy related-cost and reduce carbon emissions. Connecting a group of those in an energy sharing system can contribute to anthropogenic heat reduction and Urban Heat Island mitigation [1]. While buildings share locally generated energy, the precinct they are part of is evolving, often with no fixed system boundaries. Even when administratively bound, energy-related simulations such as solar, wind and traffic studies can lead beyond its borders. Thus, current information exchanges between design consultants and their clients using the one site, one project system often fail to provide the most sustainable precinct. Moreover, disparate models with competing stakeholders may need to interact even when interests conflict and priorities clash. For example, owners wanting to increase their energy efficiency with improved heating insulation of the buildings could render district energy generation running below capacity or even obsolete [2]. For the many different actors of such a deliberative process, it is hard to track down the cause of requirement conflicts in order to resolve them. This is particularly the case when their common point of interest is as complex as a sociotechnical precinct energy system. This makes it harder to collect and compare requirements early, in addition to being difficult to define completely. Hence, designing and reusing $M \& S$ collaboration processes remain a challenge compounded by a lack of knowledge with respect to messy decision making amongst stakeholders.

The usual method to treat conflicting requirements is to sort them according to different types, criteria and conflicts [3] in order to analyse and resolve them, while also keeping them divorced from the processes they entail. Another method is to only resolve certain types of requirements by using a chain of domains by way of eliminating coupled requirements to make them fully independent of each other [4]. The latter approach yields a process that can be automated by resolving conflicts in data of the input/output kind. The two important questions to pose, therefore, are as follows:

Q1. How do we make use of previous approaches developed for buildings but beyond the building scale and which of those can be reused? 
Q2. What needs to be changed in previous approaches?

In order to answer these questions, this paper uses modular priority loops. They capture otherwise hidden decision contexts behind stakeholder preferences relating to their business goals and their various criteria with respect to those goals. Once those contexts are captured in characteristic patterns, they will show what to change in processes already established in the industry. They can also help to combine old and complex processes in a simpler manner. Then, the structures and abstractions proposed, when combined with the power of computation, can support planning and designing more sustainable precincts with more buildings and complex facilities such as electricity and heating networks.

\section{Materials and Methods}

The methodological process steps applied in this study are shown in Figure 1a.

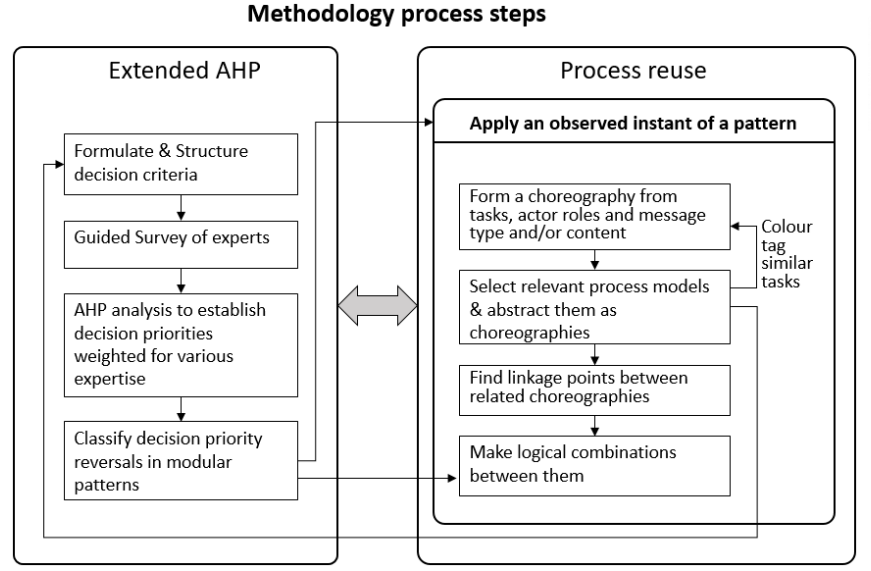

(a)

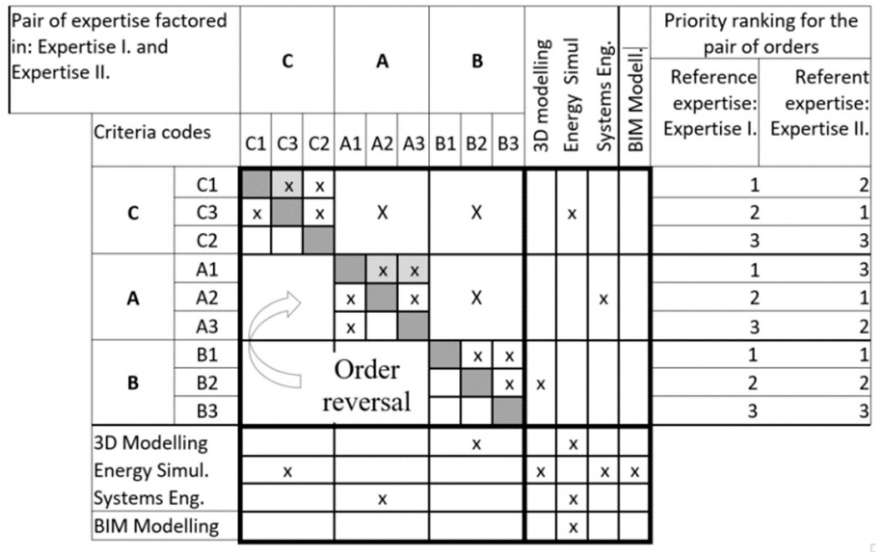

(b)

Figure 1. (a) Methodological framework. (b) Multi-domain matrix form with priority matrices in superposition to analyse order reversals (criteria codes for the reversed priority are as follows: $\mathrm{C} 1$ : record geometric operation history in the model; C3: model the state of connections; A1: model connecting objects with different levels of Detail; A2: model local and enveloping systems together; A3: model system components at different levels of detail. The rest of the criteria codes stand for the following: C2: model the state of connecting objects; B1: exchange function as part of the model; B2: request function from service provider (SP); B3: work with another SP to complete simulation).

Here, we consider requirements as they relate to some objectives or intents. They have various criteria to be fulfilled and then realised in specific process tasks. Objectives are aimed at activities and are worded as such. We posit that there exists a certain class of requirements, where one can make a more direct connection between objectives or intents and the ensuing activities. In that case, priorities of tasks directly relate to their precedence order [5]. Moreover, based on conditional and inconsistent judgments by human actors, their multi-objective requirements conflict when trying to refine modular exchanges between digital information models. For such judgments, by many accounts, the most applied multi-objective criteria analysis technique (MCDA) is the analytical hierarchy process (AHP) [6] developed by considering decision and utility theory and psychological attributes [7]. Conventional AHP does not eliminate reversals between priorities. People can change them depending on their interest, experience and the information at hand. Requirement priorities between many actors can also be intransitive due to Arrow's Impossibility Theorem [4]. Such requirements are in a coupled priority order. This means for any criteria $\mathrm{A}, \mathrm{B}$ and $\mathrm{C}$, when $\mathrm{A}>\mathrm{B}$ and $\mathrm{B}>\mathrm{C}$, implying $\mathrm{A}>\mathrm{C}$, it is still possible that $\mathrm{C}>\mathrm{A}$, where ' $>$ ' means higher priority. When priorities reverse, there can be a conflict in their order between different actors. Thus, one needs to model rank order changes with respect to process tasks, and the specific conditions for the related human judgements. 
In order to represent a rank order reversal, one can model two orders together by re-sequencing the matrix form of a graph and taking different snapshots. For juxtaposing different orders, some also apply matrix superposition as a visual aid either to model different layers of dependencies [8] or to analyse an evolving system [9]. Furthermore, a partial order can be modelled either as a Hasse diagram, graph or adjacency matrix [10]. Different aspects of such orders can be modelled in a multidomain matrix (MDM) [11]. Thus, decision conditions, their criteria order and related process tasks all can be represented in an MDM.

Using the AHP model, we have internationally surveyed a non-probabilistic sample of twelve experts similar to comparable research $[12,13]$. We posed decision criteria in limited sets, each consisting of no more than three elements. Participants were ranked to weigh and order their priorities with respect to various $M \& S$ criteria according to different expertise. To model partial order variants, we used matrix superposition. Figure 1 b shows such a matrix in an MDM. It integrates information from the following processes: (i) the ordered and ranked criteria priority, calculated using the eigenvector method of the AHP model; and (ii) the lower right matrix shows predominant interactions between the related actor roles. Parametric criteria codes are also relevant for further processing.

We then superposed pairs of the analysed priority orders and partitioned them using a modularization algorithm to capture priority reversals and identify their patterns. We then validated the approach using two real-world industry process models for collaborative digital information exchanges. One has been devised for schematic design and energy analysis [14], the other to manage design variants throughout the M\&S lifecycle [15,16]. We dubbed these the GSA and the M-K-E models, respectively.

\section{Results}

Our results show that a relatively small sample can yield a transitive order for criteria priorities calculated for specific expertise. Using our modularization algorithm, we have also identified persistent reversal patterns across various orders. They pair participants with different relevant expertise modelled as collaborating actor roles. Figure 2a shows one such pattern and its matrix form partitioned using the modularization algorithm. In order to apply the pattern to real-world process models, we abstracted them as process choreographies [17]. For comparing them to the priority orders found, we also expressed the task intent chain mapped from those orders as a choreography. Message exchange types were added, as were bars for optional participants and/or participant types. Interpreting the found priority loop pattern in such a manner proved instrumental in reusing and logically combining established industry processes. Figure $2 \mathrm{~b}$ shows such a logical combination.

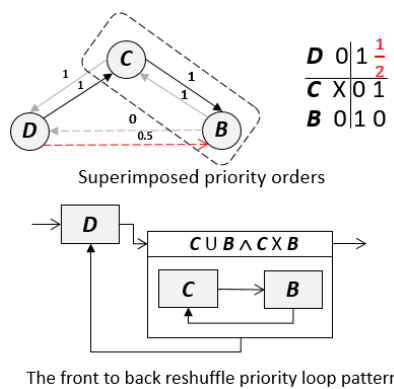

(a)

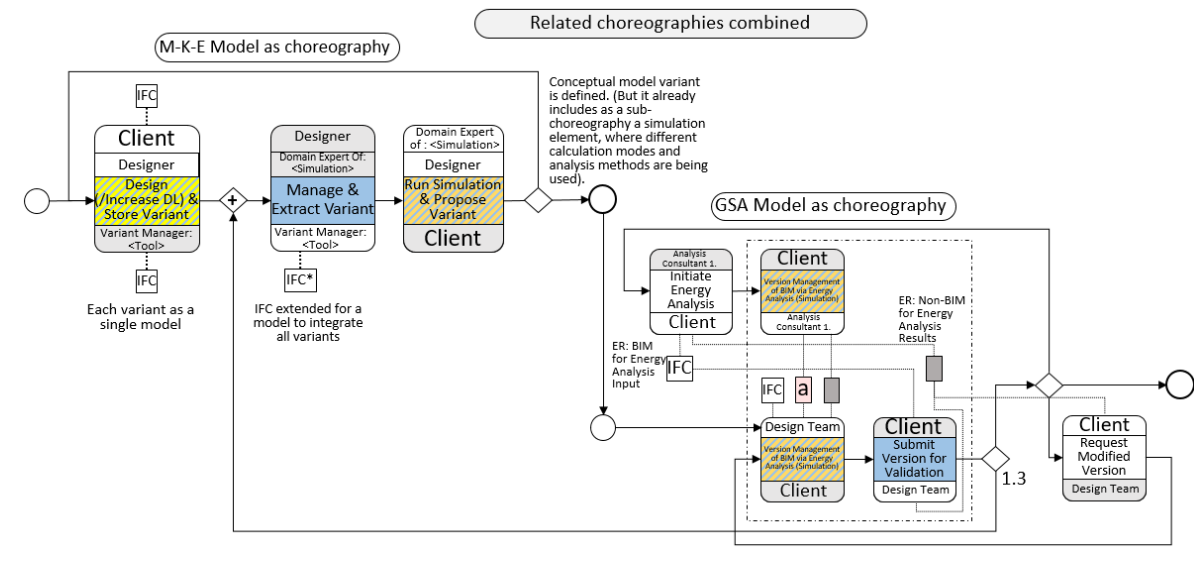

(b)

Figure 2. (a) Example partitioning of two superposed priority orders for sets of three (arbitrary vertices D, C and B are assigned to both the rows and the corresponding columns in the square matrix, where values stand for the summed weight of edges, and the mark X denotes coupling between 
submatrices. Set operators such as union (as in $\mathrm{C} \cup \mathrm{B}$ ) and Cartesian product (as in $\mathrm{C} \mathrm{X} \mathrm{B)} \mathrm{are}$ indicative for the textual composition of the module label). (b) Logical combination of choreographies for M-K-E and GSA models.

\section{Conclusions}

We have addressed the two research questions posed in Section 1 as follows. With the help of a priority reversal, found and captured in a (parametric) loop pattern with respect to specific collaborative expert roles, we have identified a higher-level abstraction (choreography) that is currently applied in the industry as process models. Based on our findings, we have also selected established and relevant process models with respect to $M \& S$ and formed choreographies from those. Then, taking a specific instance of the pattern and applying the task that related decision criteria would directly entail, we colour tagged the choreographies to find similarities and linkage points. This prompted a useful logical combination of the existing process models through their articulated choreographies. It was proposed that through such a process, a further elaboration as to what else needs to be changed and reused can be made in the future.

Author Contributions: Conceptualization, methodology and formal analysis: O.N.; writing—review and editing: O.N. and G.P.; supervision: H.H. and G.P. All authors have read and agreed to the published version of the manuscript.

Funding: This research was partly funded by the Cooperative Research Centre for Low Carbon Living under Project No RP2011: PIM-An Open Digital Information Standard throughout the Urban Development Lifecycle.

Institutional Review Board Statement: The study was conducted in accordance with the Declaration of Helsinki, and approved by the Ethics Committee of UNSW Built Environment HREAPE protocol code HC190225 approved 12 June 2019.

Informed Consent Statement: Informed consent was obtained from all subjects involved in the study. Data Availability Statement: Not applicable.

Acknowledgments: We thank the PIM research team for their generous technical support.

Conflicts of Interest: The authors declare no conflict of interest.

\section{References}

1. Mavrigiannaki, A.; Pignatta, G.; Assimakopoulos, M.; Isaac, M.; Gupta, R.; Kolokotsa, D.; Laskari, M.; Saliari, M.; Meir, I.A.; Isaac, S. Examining the benefits and barriers for the implementation of net zero energy settlements. Energy Build. 2021, $230,110564$. [CrossRef]

2. Cajot, S.; Peter, M.; Bahu, J.-M.; Guignet, F.; Koch, A.; Maréchal, F. Obstacles in energy planning at the urban scale. Sustain. Cities Soc. 2017, 30, 223-236. [CrossRef]

3. Salado, A.; Nilchiani, R. Adaptive Requirements Prioritization (ARP): Improving Decisions between Conflicting Requirements. Syst. Eng. 2015, 18, 472-490. [CrossRef]

4. Suh, N.P. Axiomatic Design: Advances and Applications; Oxford University Press: New York, NY, USA, 2001.

5. Newhouse, O.; Han, H.; Pignatta, G. Integrating the Analytic Hierarchy Process (AHP) in process engineering for infrastructure Modelling and Simulation (M\&S). In Proceedings of the CEES2021 Proceedings, Coimbra, Portugal, $12-15$ October 2021.

6. Wallenius, J.; Dyer, J.S.; Fishburn, P.C.; Steuer, R.E.; Zionts, S.; Deb, K. Multiple Criteria Decision Making, Multiattribute Utility Theory: Recent Accomplishments and What Lies Ahead. Manag. Sci. 2008, 54, 1336-1349. [CrossRef]

7. Saaty, T.L. How to Make a Decision: The Analytic Hierarchy Process. Interfaces 1994, 24, 19-43. [CrossRef]

8. Lindemann, U.; Maurer, M.; Braun, T. Structural Complexity Management: An Approach for the Field of Product Design; Springer: Berlin, Germany, 2009; ISBN 9783540878896.

9. Fernandez, A.; Bergel, A. A domain-specific language to visualize software evolution. Inf. Softw. Technol. 2018, 98, 118-130. [CrossRef]

10. Baldwin, A.; Austin, S.; Waskett, P. Process modelling for planning, managing and control of collaborative design. In Collaborative Construction Information Management; Shen, G., Brandon, P.S., Baldwin, A.N., Eds.; Spon Press: London, UK, 2009; pp. 68-79, ISBN 0203883632. 
11. Kreimeyer, M.; Lindemann, U. Complexity Metrics in Engineering Design: Managing the Structure of Design Processes; Springer Science \& Business Media: New York, NY, USA, 2011; ISBN 9783642209635.

12. Atazadeh, B. Building Information Modelling for Urban Land Administration. Ph.D. Thesis, University of Melbourne, Parkville VIC, Australia, 2017.

13. Almeida, D.; Pradhan, N.; Muniz, J., Jr. Assessment of ISO 9001:2015 implementation factors based on AHP: Case study in Brazilian automotive sector. Int. J. Qual. Reliab. Manag. 2018, 35, 1343-1359. [CrossRef]

14. US General Services Administration. Information Delivery Manual for BIM Based Energy Analysis as Part of the Concept Design BIM 2010; US General Services Administration: Washington, DC, USA, 2009.

15. Exner, H.; Abualdenien, J.; König, M.; Borrmann, A. Managing Building Design Variants at Multiple Development Levels. In Proceedings of the 36th International Council for Research and Innovation in Building and Construction (CIB W78), Newcastle, UK, 18-20 September 2019.

16. Mattern, H.; Konig, M. BIM-based modeling and management of design options at early planning phases. Adv. Eng. Inform. 2018, 38, 316-329. [CrossRef]

17. OMG. Business Process Model and Notation (bpmn) Version 2.0. 2011. Available online: http://www.omg.org/spec/BPMN/2.0 (accessed on 1 September 2021). 